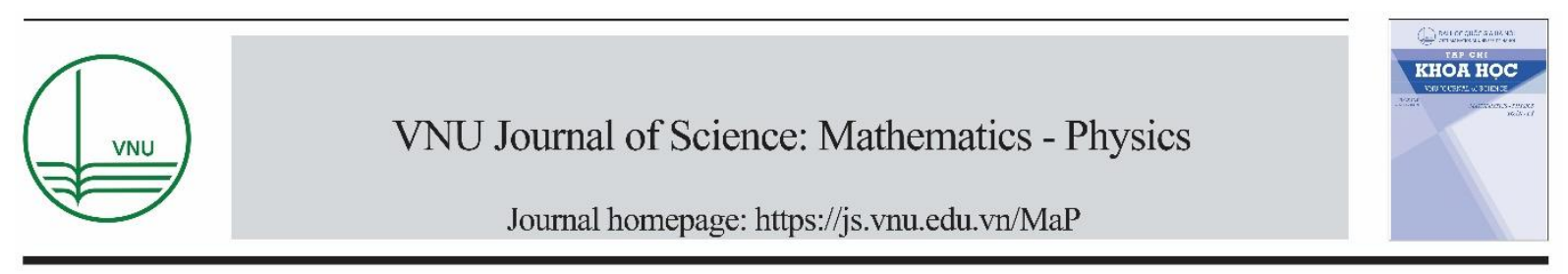

\title{
Synthesis and Characterization of $\mathrm{NiFe}_{2} \mathrm{O}_{4} / \mathrm{ZnO}$ core-shell Nanocomposites
}

\author{
Dinh Khac Huy ${ }^{1}$, Nguyen Phuc Duong ${ }^{1, *}$, To Thanh Loan ${ }^{1}$, \\ Hoang Manh Chung ${ }^{1}$, Nguyen Kim Thanh ${ }^{2}$, Vu Van Khai ${ }^{3}$ \\ ${ }^{1}$ International Training Institute for Materials Science (ITIMS), \\ Hanoi University of Science and Technology, 1 Dai Co Viet, Hanoi, Vietnam \\ ${ }^{2}$ Le Quy Don University of Science and Technology, Hoang Quoc Viet 236, Hanoi, Vietnam \\ ${ }^{3}$ National University of Civil Engineering, 55 Giai Phong, Hanoi, Vietnam
}

Received 09 November 2018

Revised 21 December 2018; Accepted 22 December 2018

\begin{abstract}
NiFe}_{2} \mathrm{O}_{4} / \mathrm{ZnO}$ core-shell nanocomposites were prepared by two-step method. First, $\mathrm{NiFe}_{2} \mathrm{O}_{4}$ nanoparticles as the cores were synthesized by using hydrothermal route, and then modified by using sodium citrate. After that $\mathrm{ZnO}$ as the shells were coated with modified $\mathrm{NiFe}_{2} \mathrm{O}_{4}$ nanoparticles by two different chemical methods including hydrothermal and co-precipitation. The formation, crystal structure, morphology and magnetic properties of the uncoated and coated samples were investigated by using X-ray diffraction, Fourier transform infrared spectroscopy, scanning electron microscopy and vibrating sample magnetometer. It was shown that the core nanoparticles are single $\mathrm{NiFe}_{2} \mathrm{O}_{4}$ phase with cubic spinel structure. Sodium citrate was well bonded to the surface of the modified nanoparticles. Contributions of the phases in the coated samples as well as structural parameters were determined from XRD data using Rietveld refinement analysis. Magnetization of the core can be improved by adjusting the modification steps. XRD analysis result and SEM images revealed the formation of core/shell structure in the sample coated by using coprecipitation method.
\end{abstract}

Keywords: $\mathrm{NiFe}_{2} \mathrm{O}_{4} / \mathrm{ZnO}$, core-shell, morphology, crystal structure, magnetization.

\section{Introduction}

Nano-ferrites with many special properties compared to bulk materials such as high thermal stability and enhanced electrical, optical and magnetic properties have been used in many applications including magnetic recording, magnetic resonance imaging (MRI) enhancement, catalysis, magnetically guided

\footnotetext{
*Corresponding author. Tel.: 84-915527063.

Email: duong@itims.edu.vn

https//doi.org/ 10.25073/2588-1124/vnumap.4297
} 
drug delivery, power transformers and telecommunication applications as well as sensors and pigments [1-3]. Due to exhibiting ferrimagnetic properties combined with relatively low electrical properties, nickel ferrite $\left(\mathrm{NiFe}_{2} \mathrm{O}_{4}\right)$ is one of the most important materials in the inverse spinel family [4]. Meanwhile, $\mathrm{ZnO}$ has been gained a lot of attentions related to its desirable properties including electric, photonic and oxidation resistance, non- toxic, wide band gap $\left(E_{\mathrm{g}}=3.37 \mathrm{eV}\right)$ [5]. Combining $\mathrm{NiFe}_{2} \mathrm{O}_{4}$ with $\mathrm{ZnO}$ to form hybrid, composite or core/shell structures is expected to promote the advantages of both materials. The reported studies on combined $\mathrm{NiFe}_{2} \mathrm{O}_{4} / \mathrm{ZnO}$ nanoparticles have shown their applicability for photocatalytic dye degradation in which they can be easily separated from the reacted solution by using external magnet $[6,7]$. For efficient application, it is necessary to stabilize and enhance magnetization of nickel ferrite nanoparticles. Many methods have been used to synthesize $\mathrm{NiFe}_{2} \mathrm{O}_{4}$ nanoparticles such as co-precipitation [8], sol-gel [9], egg-white precursor [2] and hydrothermal [3, 6], in which hydrothermal method exhibits many advantages over the others such as high crystallinity, simplicity and low temperature usage. By using this method, it is possible to fabricate nickel ferrite with high magnetization and good separation as the core for the $\mathrm{NiFe}_{2} \mathrm{O}_{4} / \mathrm{ZnO}$ core-shell nanocomposites.

In this paper, we present a detailed study on synthesis and characterization of $\mathrm{NiFe}_{2} \mathrm{O}_{4} / \mathrm{ZnO}$ coreshell nanocomposites in which $\mathrm{NiFe}_{2} \mathrm{O}_{4}$ nanoparticles were synthesized by using hydrothermal method and then modified by sodium citrate. We have attempted to coat $\mathrm{ZnO}$ on the modified $\mathrm{NiFe}_{2} \mathrm{O}_{4}$ nanoparticles by using two different chemical methods including hydrothermal and co-precipitation. The magnetic core and coated samples were characterized by XRD, SEM, FTIR and VSM techniques.

\section{Experiments}

Synthesis

A two-step method was used to synthesize $\mathrm{NiFe}_{2} \mathrm{O}_{4} / \mathrm{ZnO}$ core-shell nanocomposites. In the first step, magnetic $\mathrm{NiFe}_{2} \mathrm{O}_{4}$ cores were prepared by using hydrothermal method. Then $\mathrm{ZnO}$ shells were coated on the core to form core-shell structure.

Synthesis of $\mathrm{NiFe}_{2} \mathrm{O}_{4}$ nanoparticles: The solutions of $\mathrm{Ni}\left(\mathrm{NO}_{3}\right)_{2} 0.05 \mathrm{M}$ and $\mathrm{Fe}\left(\mathrm{NO}_{3}\right)_{3} 0.05 \mathrm{M}$ with molar ratio 1:2 were dissolved in $50 \mathrm{ml}$ distilled water and magnetically stirred. After 15 minutes, $50 \mathrm{ml}$ solution of $\mathrm{NaOH} 0.4 \mathrm{M}$ was dropped into the mixed solution with vigorously stirring until $\mathrm{pH}$ value reaches to 9. The solution was stirred for additional 30 minutes and then transferred into a $200 \mathrm{ml}$ Teflonlined autoclave. The sealed autoclave was heated at $180^{\circ} \mathrm{C}$ for $9 \mathrm{~h}$ and cooled down to room temperature. Finally, the nickel ferrite nanoparticles were collected by a permanent magnet and washed 3 times by distilled water until $\mathrm{pH}=7$.

Modification of $\mathrm{NiFe}_{2} \mathrm{O}_{4}$ nanoparticles by sodium citrate: Sodium citrate solution was prepared by reaction of $\mathrm{NaOH}$ with citric acid. The $\mathrm{NiFe}_{2} \mathrm{O}_{4}$ nanoparticles $(0.4 \mathrm{~g})$ and sodium citrate $(100 \mathrm{ml}, 0.1 \mathrm{M})$ were mixed together in three- neck flask. The mixture was vigorously stirred at $80^{\circ} \mathrm{C}$ for $3 \mathrm{~h}$. The steam was shoved out by a vacuum pump. The precipitate was collected by a permanent magnet and washed several times with acetone. The samples were denoted as NF1, NF2 and NF3 for those modified with hydrothermal treatment, non-modified and modified after hydrothermal treatment, respectively.

Synthesis of $\mathrm{NiFe}_{2} \mathrm{O}_{4} / \mathrm{ZnO}$ core-shell nanocomposites: Modified $\mathrm{NiFe}_{2} \mathrm{O}_{4}$ nanoparticles were dissolved in $100 \mathrm{ml}$ distilled water. After removing the excessive particles by using a magnet, the mixture was divided into two equal parts (solution 1 and solution 2 ) to carry out coating experiment with $\mathrm{ZnO}$. After that, $25 \mathrm{ml}$ solution of $\mathrm{Zn}(\mathrm{AC})_{2} 0.1 \mathrm{M}$ was added to each solution and magnetically stirred for 15 minutes. Then $25 \mathrm{ml}$ solution of $\left(\mathrm{NH}_{4}\right)_{2} \mathrm{CO}_{3} 0.06 \mathrm{M}$ was added dropwise to each solution. Solution 1 was transferred to a Teflon-lined autoclave and heated at $130^{\circ} \mathrm{C}$ for $2 \mathrm{~h}$ as hydrothermal treatment. Solution 
2 was filtered and washed 3 times by distilled water to collect nanoparticles, then heated at $350^{\circ} \mathrm{C}$ for $2 \mathrm{~h}$ as co-precipitation treatment (described in [10]) to form $\mathrm{ZnO}$ shell. Two $\mathrm{NiFe}_{2} \mathrm{O}_{4} / \mathrm{ZnO}$ core-shell nanocomposites samples obtained from solution 1 and solution 2 were grinded into powder and denoted as NFZ1 and NFZ2, respectively.

\section{Characterization techniques}

The crystal structure and phase formation of the samples were investigated by X-ray diffraction (Siemens D5000 X-ray Diffractometer with $\mathrm{Cu} K_{\alpha}$ radiation, $\lambda=1.5406 \AA$ ). The diffraction data were analyzed using Rietveld method with the help of FullProf program [11]. The diffraction peaks were modeled by pseudo-Voigt function which is a sum of Gaussian and Lorentzian functions [12]. The refinement fitting quality was checked by goodness of fit $\left(\chi^{2}\right)$ and weighted profile $R$-factor $\left(R_{\mathrm{wp}}\right)$. The calculated results are accepted with $\chi^{2}$ should approach 1 and $R_{\mathrm{wp}}$ must be close to or less than $10 \%$ [13].

Infrared (IR) absorption spectra of the samples were recorded on Perkin Elemer FT-IR spectrum one spectrometer in the frequency range 400-4000 $\mathrm{cm}^{-1}$. Field Emission-Scanning Electron Microscopy (FESEM) (JEOL JSM-7600 F) was used to examine the grain size and morphology. Magnetization curves were measured using a vibrating sample magnetometer (VSM) in applied magnetic fields up to $10 \mathrm{kOe}$.

\section{Results and discussion}

\section{Characterization of $\mathrm{NiFe}_{2} \mathrm{O}_{4}$ nanoparticles}

One of the XRD diffraction patterns and its Rietveld refinement of nickel ferrite samples are shown in Fig. 1. As seen, the XRD pattern of the $\mathrm{NiFe}_{2} \mathrm{O}_{4}$ nanoparticles shows only nickel ferrite phase in which the diffraction peaks seen at the $2 \theta$ values of $30.26^{\circ}, 35.65^{\circ}, 37.29^{\circ}, 43.33^{\circ}, 47.44^{\circ}, 53.76^{\circ}, 57.31^{\circ}$, $62.94^{\circ}, 66.18^{\circ}, 67.25^{\circ}$ correspond to the planes of (220), (311), (222), (400), (331), (422), (511), (440), (531) and (442), respectively (JCPDS no. 54-0964). The structural parameters of the samples were well refined using the standard model of spinel ferrite within the cubic symmetry (space group $F d 3 m$ ). Lattice constant value of the $\mathrm{NiFe}_{2} \mathrm{O}_{4}$ samples $(a=8.346 \AA)$ is higher than that reported for $\mathrm{NiFe}_{2} \mathrm{O}_{4}$ bulk sample $(a=8.339 \AA)$ in the standard data (JCPDS: 10-0325) but in good agreement with that reported previously for $\mathrm{NiFe}_{2} \mathrm{O}_{4}$ nanoparticles [3, 14].

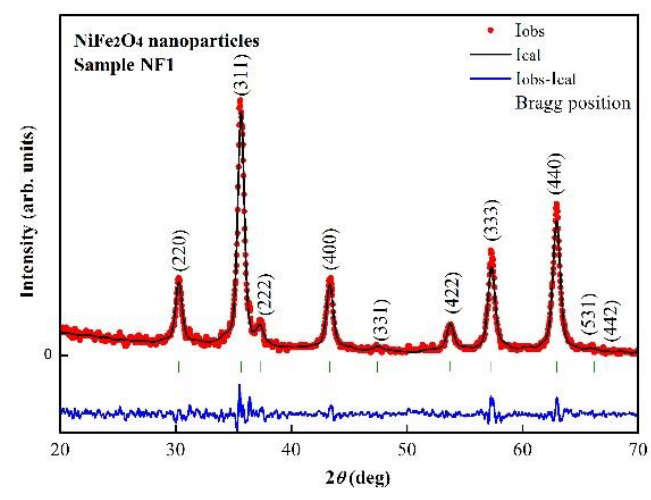

Figure 1. X-ray diffraction pattern of the $\mathrm{NiFe}_{2} \mathrm{O}_{4}$ sample and processed by the Rietveld method. Fitting quality: $\chi^{2}=1.38$ and $R_{\mathrm{wp}}=10.7 \%$. The experimental points as well as calculated and difference functions are indicated. 
The average size of coherent scattering region $D$ (usually referred as crystallite size) of the samples was determined based on the Rietveld method using the Fullprof program in which the instrumental resolution function was included. The crystallite size of the $\mathrm{NiFe}_{2} \mathrm{O}_{4}$ nanoparticles was obtained to be $11.1 \mathrm{~nm}$.

In order to testify the absorption of carboxyl groups on the nanoparticle surface, FTIR analysis of the modified samples (NF1 and NF3) was performed and presented in Figure 2. It can be seen that the FTIR spectra of both samples exhibit the characteristic absorption peaks of carboxyl group of sodium citrate at $1580 \mathrm{~cm}^{-1}$ and $1390 \mathrm{~cm}^{-1}$ due to the $-\mathrm{COO}-$ symmetric and antisymmetric stretching respectively. The result indicated the presence of $\mathrm{COO}-$ group in the investigated samples. In this case, sodium citrate was bonded on the surface of the nanoparticles through the interaction between the COOgroup of citrate and the $\mathrm{Fe}$ atom as revealed previously by Cheng et al [15]. The $\mathrm{NiFe}_{2} \mathrm{O}_{4}$ samples also show an -OH absorption peak at around $3600 \mathrm{~cm}^{-1}$ due to the physical adsorption of water. The strong bands of both samples observed at about $530 \mathrm{~cm}^{-1}$ correspond to $\mathrm{Fe}-\mathrm{O}$ vibration modes of the tetrahedral site.

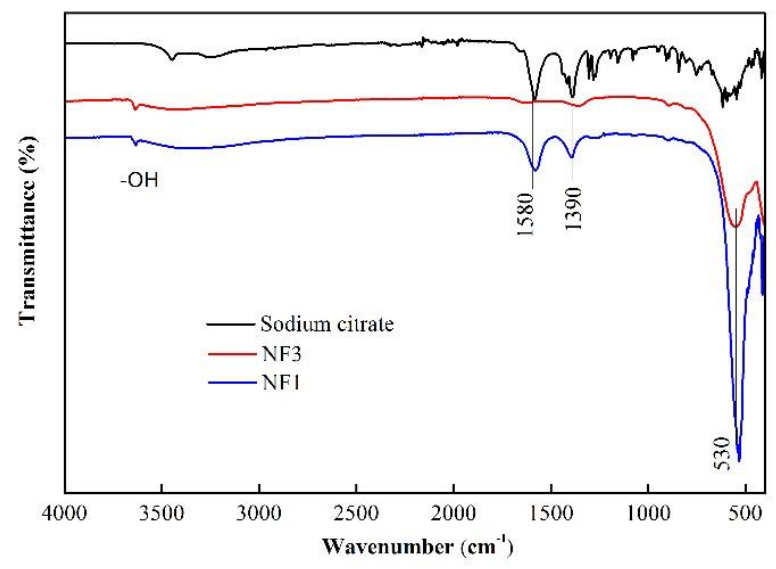

Figure 2. FTIR absorption spectra of the modified samples (NF1 and NF3).

The magnetization curves of the $\mathrm{NiFe}_{2} \mathrm{O}_{4}$ samples (NF1, NF2 and NF3) measured at room temperature are shown in Figure 3. A common feature of the $M-H$ curves indicates that the magnetization of the samples is not fully saturated up to highest investigated magnetic field. This behaviour is attributed to random distribution of the magnetization directions of nanoparticles in the samples and the interactions between them [14]. In these cases, the law of approach to saturation can be applied to estimate the saturation magnetization $M_{\mathrm{s}}$ of the samples, by which the magnetization is expressed as a function of the magnetic field as follows [16]:

$$
M=M_{\mathrm{s}}\left(1-a / H^{1 / 2}-b / H^{2}\right)
$$

where the term $a / H^{1 / 2}$ arises from defects in the particles and the term $b / H^{2}$ is attributed to the effective anisotropy energy of the samples. The obtained $M_{\mathrm{s}}$ values of the NF1, NF2 and NF3 samples are 48.33, 40.58 and $39.91 \mathrm{emu} / \mathrm{g}$, respectively. These values are lower than saturation magnetization of the bulk $\mathrm{NiFe}_{2} \mathrm{O}_{4}\left(M_{\mathrm{s}}^{\text {bulk }}=55 \mathrm{emu} / \mathrm{g}\right.$ [17] $)$ but much higher than those reported for the $\mathrm{NiFe}_{2} \mathrm{O}_{4}$ nanoparticles prepared by other methods $[2,18]$. The reduction of magnetization of the nanoparticles compared to that of the bulk material can be well explained due to the spin disorder in surface shell regions [14]. As seen in the Figure 3, the magnetization of the sample modified after hydrothermal treatment (NF3) is slightly lower than that of the non-modified sample (NF2). Meanwhile, the $\mathrm{NiFe}_{2} \mathrm{O}_{4}$ sample modified with hydrothermal treatment (NF1) has significantly higher $M_{\mathrm{s}}$ than that of the NF2 
sample. This observation can be attributed to the presence of $\mathrm{Fe}^{2+}$ ion formed when $\mathrm{NiFe}_{2} \mathrm{O}_{4}$ nanoparticles was modified by sodium citrate within hydrothermal treatment. The sample NF1 was chosen as the core to synthesize $\mathrm{NiFe}_{2} \mathrm{O}_{4} / \mathrm{ZnO}$ core/shell nanoparticles.

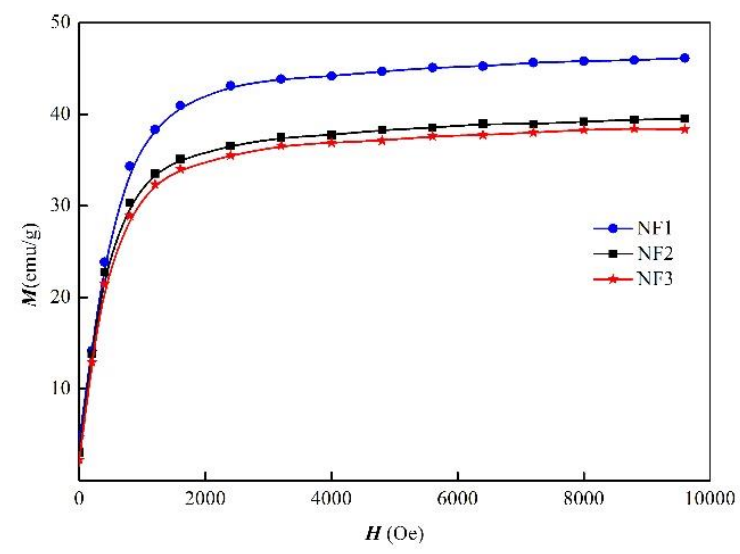

Figure 3. $M-H$ curves measured at $300 \mathrm{~K}$ of the $\mathrm{NiFe}_{2} \mathrm{O}_{4}$ samples (NF1, NF2, and NF3).

\section{Characterization of NiFe2O4/ZnO core/shell nanoparticles}

Figure 4 shows the XRD patterns of the $\mathrm{NiFe}_{2} \mathrm{O}_{4} / \mathrm{ZnO}$ core/shell samples coated by using different methods (described in 2.1). It can be seen that $\mathrm{ZnO}$ phase was not formed in the sample coated by using hydrothermal method (NFZ1). In this case, ZnO exists in the amorphous form. The NFZ1 sample contains only $\mathrm{NiFe}_{2} \mathrm{O}_{4}$ and $\alpha-\mathrm{Fe}_{2} \mathrm{O}_{3}$ phases. The presence of $\alpha-\mathrm{Fe}_{2} \mathrm{O}_{3}$ in the sample can be explained due to the formation of $\mathrm{Fe}^{2+}$ ions during modification process of $\mathrm{NiFe}_{2} \mathrm{O}_{4}$ nanoparticles by sodium citrate, and then divalent iron ions were oxidized to form $\alpha-\mathrm{Fe}_{2} \mathrm{O}_{3}$ in $\mathrm{ZnO}$ coating process by hydrothermal method. Meanwhile, $\mathrm{NiFe}_{2} \mathrm{O}_{4}$ and crystalline phase of $\mathrm{ZnO}$ were observed clearly in the XRD pattern of the sample coated by using co-precipitation method (NFZ2). For demonstration, the XRD pattern of the NFZ2 sample and its Rietveld refinement are shown in Figure 5. $\mathrm{NiFe}_{2} \mathrm{O}_{4}$ phase was well refined in inverse spinel structure with space group $F d 3 m$, while hexagonal of $\mathrm{ZnO}$ phase with space group $\mathrm{P}_{3} m c$. The refinement result indicated that the sample contains $\mathrm{NiFe}_{2} \mathrm{O}_{4}$ and $\mathrm{ZnO}$ phases, none of other impurities was observed. The refined values of structural parameters including lattice parameters $(a, c)$, phase contents and crystallite size of the samples are given in Table 1.

Table 1. Phase contents, lattice parameters, crystallite size, grain size and saturation magnetization at room temperature of the uncoated and coated samples. Statistical errors are indicated in the last significant digit.

\begin{tabular}{|c|c|c|c|c|c|c|}
\hline Sample & Phase & Content, \% & $\begin{array}{l}\text { Lattice parameter, } \\
\AA\end{array}$ & $\begin{array}{l}\text { Crystallite size } \\
\mathrm{D}, \mathrm{nm}\end{array}$ & $\begin{array}{l}\text { Grain size, } \\
\mathrm{nm}\end{array}$ & $\begin{array}{l}M_{\mathrm{s}} \text { at room } \\
\text { temperature, emu/g }\end{array}$ \\
\hline NF1 & $\mathrm{NiFe}_{2} \mathrm{O}_{4}$ & 100 & \multirow{3}{*}{$\begin{array}{l}a=8.346(1) \\
a=3.249(1) \\
c=5.210(2) \\
a=8.346(1)\end{array}$} & $11.1(1)$ & $8-18$ & 48.33 \\
\hline $\mathrm{ZnO}$ & $\mathrm{ZnO}$ & 100 & & $12.8(1)$ & \multirow[t]{2}{*}{ - } & \multirow[t]{2}{*}{ - } \\
\hline \multirow[b]{2}{*}{ NFZ1 } & $\mathrm{NiFe}_{2} \mathrm{O}_{4}$ & 78 & & $11.2(1)$ & & \\
\hline & $\alpha-\mathrm{Fe}_{2} \mathrm{O}_{3}$ & 22 & $\begin{array}{l}a=5.038(1) \\
c=13.772(2)\end{array}$ & $11.3(2)$ & - & 17.44 \\
\hline \multirow[b]{2}{*}{ NFZ2 } & $\mathrm{NiFe}_{2} \mathrm{O}_{4}$ & 41 & $a=8.348(1)$ & $11.3(1)$ & \multirow[b]{2}{*}{$28-40$} & \multirow[b]{2}{*}{20.22} \\
\hline & $\mathrm{ZnO}$ & 59 & $\begin{array}{l}a=3.249(1) \\
c=5.210(2)\end{array}$ & $12.8(1)$ & & \\
\hline
\end{tabular}




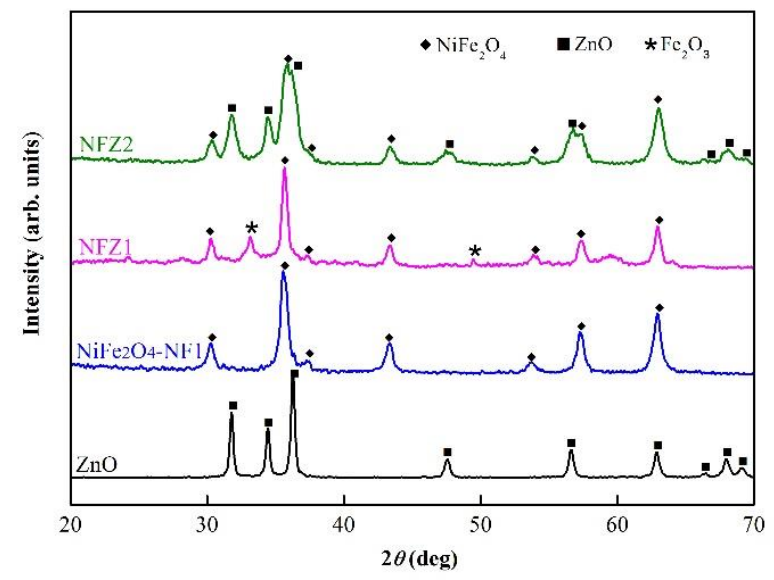

Figure 4. XRD patterns of the coated samples (NFZ1 and NFZ2), the core sample NF1 and ZnO.

As seen in Table 1, the lattice constant as well as crystallite size of $\mathrm{NiFe}_{2} \mathrm{O}_{4}$ and $\mathrm{ZnO}$ phases in the NFZ2 sample is almost similar to those of the original samples (NF1 and ZnO). Only a slight increase of lattice constant was observed in the NFZ2 sample that can be related to the changes in spinel structure of $\mathrm{NiFe}_{2} \mathrm{O}_{4}$ core such as cations redistribution [14] or the diffusion of larger zinc ions into the spinel structure $\left(\mathrm{r}_{\mathrm{Zn}}{ }^{2+}=0.88 \AA, \mathrm{r}_{\mathrm{Ni}}{ }^{2+}=0.83 \AA, \mathrm{ree}^{3+}=0.785 \AA\right.$ [19]). The $\mathrm{NiFe}_{2} \mathrm{O}_{4}: \mathrm{ZnO}$ molar ratio of the sample was found to be $41: 59$. The contributions of $\mathrm{NiFe}_{2} \mathrm{O}_{4}$ and $\mathrm{ZnO}$ phases in the NFZ2 sample are shown in the inset of Figure 5.

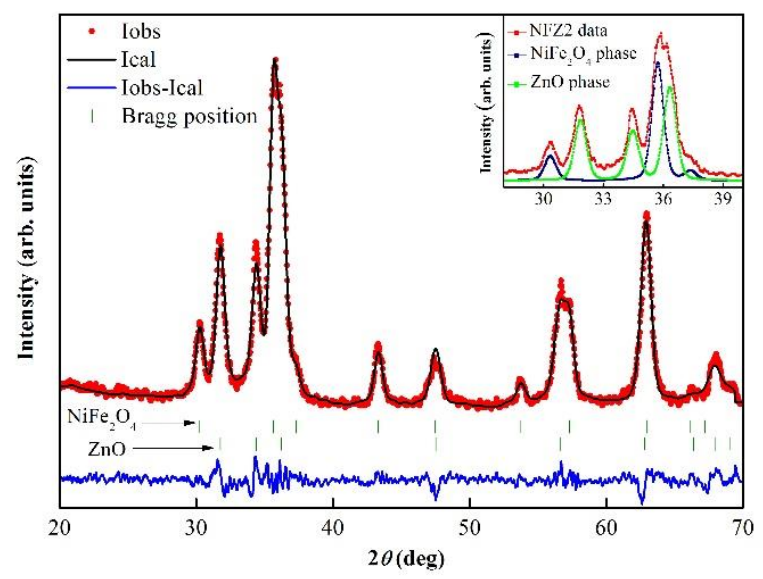

Figure 5. XRD pattern of the NFZ2 sample and processed by the Rietveld method. Fitting quality: $\chi^{2}=1.34$ and $R_{\mathrm{wp}}=8.3 \%$. The experimental points as well as calculated and difference functions are indicated. The inset illustrates the contributions to the intensity from $\mathrm{NiFe}_{2} \mathrm{O}_{4}$ and $\mathrm{ZnO}$ phases in the $2 \theta$ range from $28^{\circ}$ to $40^{\circ}$.

The morphologies of the uncoated (NF1) and coated (NFZ2) samples characterized by FESEM are presented in Figure 6. As seen in Figure 6a grains of the NF1 sample are almost cubic, grain size distributes in range of $8-18 \mathrm{~nm}$, which is in good agreement with the average crystallite size estimated from XRD. Whereas, grains of the NFZ2 sample (Figure 6b) were observed to be non-uniform with sizes from 28 to $40 \mathrm{~nm}$. The grain sizes are larger than crystallite sizes of both $\mathrm{NiFe}_{2} \mathrm{O}_{4}$ and $\mathrm{ZnO}$ phases 
in the sample (see Table 1) indicating that the grains may contain from a few crystallites of $\mathrm{NiFe}_{2} \mathrm{O}_{4}$ and/or $\mathrm{ZnO}$.
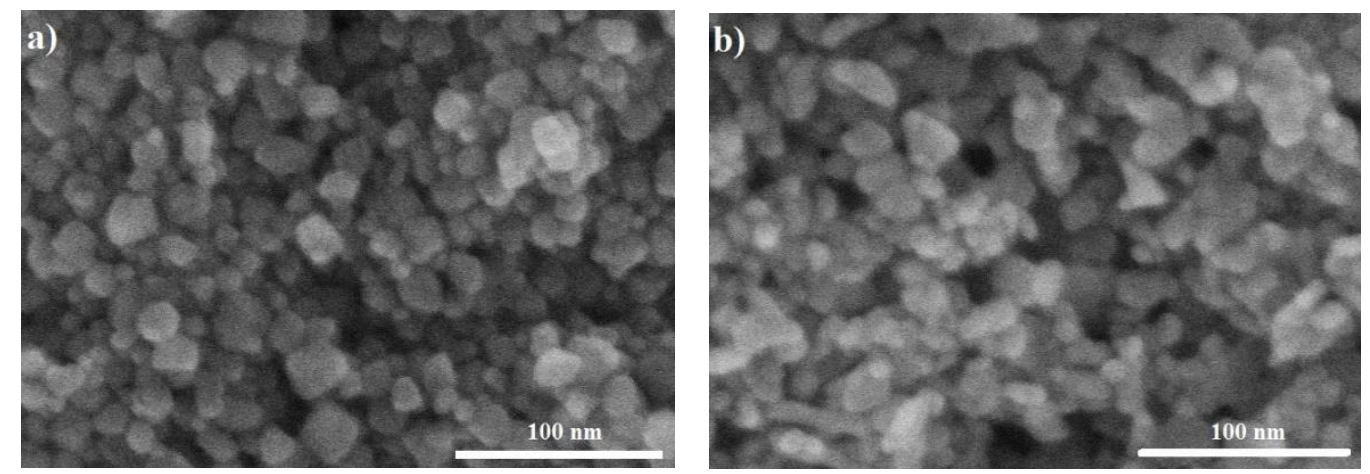

Figure 6. SEM image of a) NF1 sample and b) NFZ2 sample.

Figure 7 shows the magnetization curves of the coated samples measured at room temperature. The saturation magnetization of the samples calculated using Eq. (1) was listed in Table 1. As seen, the $M_{\mathrm{s}}$ values of NFZ1 and NFZ2 samples are 20.22 and $17.44 \mathrm{emu} / \mathrm{g}$, respectively, those are much lower than saturation magnetization of the $\mathrm{NiFe}_{2} \mathrm{O}_{4}$ core sample $\left(M_{\mathrm{s}}{ }^{\text {core }}=48.33 \mathrm{emu} / \mathrm{g}\right)$. The decrease of magnetization of the coated samples can be explained by several reasons. The first one is the contribution of nonmagnetic phases including $\mathrm{ZnO}$ and $\alpha-\mathrm{Fe}_{2} \mathrm{O}_{3}$ to total weight. The sample coated by using hydrothermal method (NFZ1) contains both $\mathrm{ZnO}$ and $\alpha-\mathrm{Fe}_{2} \mathrm{O}_{3}$ impurities as estimated from XRD analysis, and hence its $M_{\mathrm{s}}$ value is lower than that of the sample coated by using co-precipitation method (NFZ2). Another reason can be attributed to the valence change of iron ion in the coated samples. As mentioned above, modification of $\mathrm{NiFe}_{2} \mathrm{O}_{4}$ nanoparticles by sodium citrate within hydrothermal treatment can engender the appearance of $\mathrm{Fe}^{2+}$ ions. These divalent iron ions can change to trivalent ions during $\mathrm{ZnO}$ coating process that contributes to the reduction of magnetization. Besides, reported studies on spinel ferrite nanoparticles coated with $\mathrm{ZnO}$ indicated that the interaction of magnetic core with $\mathrm{ZnO}$ shell and magnetic shielding between the particles cause a decrease of magnetic moment at the coreshell interface [20]. Moreover, the magnetization of the coated samples can also be affected by the structure effects which were raised due to the coating treatment such as the redistribution of cations in spinel structure of $\mathrm{NiFe}_{2} \mathrm{O}_{4}$ core or the diffusion of $\mathrm{Zn}$ ions into the spinel structure as discussed in XRD analysis.

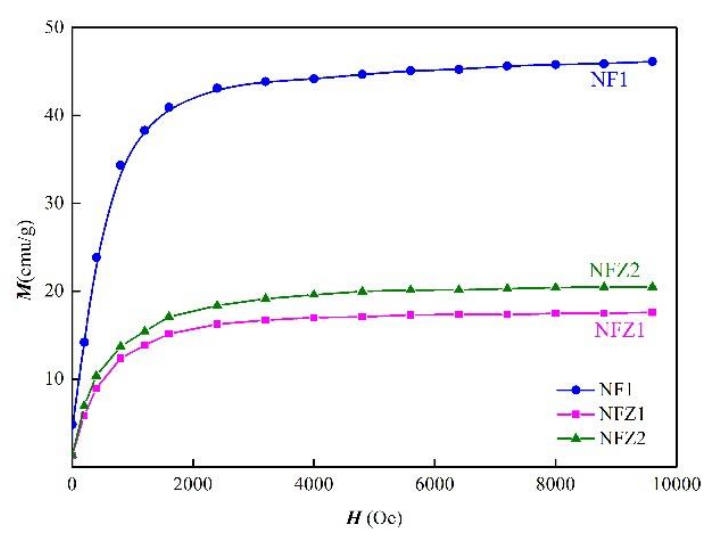

Figure 7. $M-H$ curves measured at room temperature of the $\mathrm{NiFe}_{2} \mathrm{O}_{4}$ core and coated samples 


\section{Conclusion}

In summary, we have successfully synthesized $\mathrm{NiFe}_{2} \mathrm{O}_{4} / \mathrm{ZnO}$ core/shell nanoparticles by using a combination of hydrothermal and co-precipitation methods. In the sample, $\mathrm{NiFe}_{2} \mathrm{O}_{4}$ and $\mathrm{ZnO}$ phases were crystallized completely. Grains were observed to be a set of these phases. Magnetization of the core was enhanced significantly in the case that the $\mathrm{NiFe}_{2} \mathrm{O}_{4}$ nanoparticles were modified within hydrothermal treatment. Sodium citrate confirmed to be well bonded on surface of the modified nanoparticles. Our work showed that the combination of hydrothermal and co-precipitation methods is an effective solution to fabricate $\mathrm{NiFe}_{2} \mathrm{O}_{4} / \mathrm{ZnO}$ core/shell nanoparticles with high magnetization.

\section{Acknowledgments}

This research is funded by the Vietnam National Foundation for Science and Technology Development (NAFOSTED) under grant number 103.02-2017.31.

\section{References}

[1] Goldman, "Modern Ferrite Technology," 2 Ed., Springer, Pittsburg, 2006.

[2] S. Maensiri, C. Masingboon, B. Boonchom, and S. Seraphin, "A simple route to synthesize nickel ferrite $\left(\mathrm{NiFe}_{2} \mathrm{O}_{4}\right)$ nanoparticles using egg white,” Scr. Mater., vol. 56, no. 9, pp. 797-800, 2007.

[3] K. C. B. Naidu and W. Madhuri, "Hydrothermal synthesis of $\mathrm{NiFe}_{2} \mathrm{O}_{4}$ nanoparticles : structural , morphological , optical , electrical and magnetic properties," vol. 40, no. 2, pp. 417-425, 2017.

[4] U. Kurtan, H. Güngüneş, H. Sözeri, and A. Baykal, "Synthesis and characterization of monodisperse $\mathrm{NiFe}_{2} \mathrm{O}_{4}$ nanoparticles,” Ceram. Int., vol. 42, no. 7, pp. 7987-7992, 2016.

[5] J. T. Adeleke, T. Theivasanthi, M. Thiruppathi, M. Swaminathan, T. Akomolafe, and A. B. Alabi, "Photocatalytic degradation of methylene blue by $\mathrm{ZnO} / \mathrm{NiFe}_{2} \mathrm{O}_{4}$ nanoparticles," Appl. Surf. Sci., vol. 455, pp. 195-200, 2018.

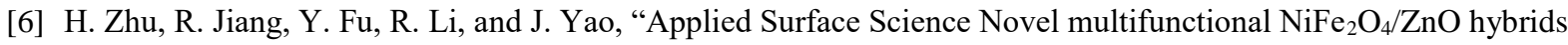
for dye removal by adsorption, photocatalysis and magnetic separation,” Appl. Surf. Sci., vol. 369, pp. 1-10, 2016.

[7] J. Jiang, L. H. Ai, L. C. Li, and H. Liu, "Facile fabrication and characterization of $\mathrm{NiFe}_{2} \mathrm{O}_{4} / \mathrm{ZnO}$ hybrid nanoparticles,” J. Alloys Compd., vol. 484, no. 1-2, pp. 69-72, 2009.

[8] Y. Shi, J. Ding, X. Liu, and J. Wang, " $\mathrm{NiFe}_{2} \mathrm{O}_{4}$ ultrafine particles prepared by co-precipitation/mechanical alloying,” J. Magn. Magn. Mater., vol. 205, no. 2-3, pp. 249-254, 1999.

[9] P. Lavela and J. L. Tirado, " $\mathrm{CoFe}_{2} \mathrm{O}_{4}$ and $\mathrm{NiFe}_{2} \mathrm{O}_{4}$ synthesized by sol-gel procedures for their use as anode materials for Li ion batteries," J. Power Sources, vol. 172, no. 1, pp. 379-387, 2007.

[10] T. D. H. To Thanh Loan, Nguyen Kim Thanh, Nguyen Phuc Duong, "Synthesis, Structural Characterization, Oxidation State and magnetic Properties of $\mathrm{Fe}_{3} \mathrm{O}_{4} / \mathrm{ZnO}$ Core/shell Nanoparticles," in The 3rd International Conference on Advanced Materials and nanotechnology, pp. 158-163, 2016.

[11] J. Rodriguez-carvajal, "Structural Analysis from Powder Diffraction Data The Rietveld Method," Ec. Themat. Cristallogr. neutrons, vol. 418, pp. 73-95, 1997.

[12] D. Balzar, Voigt-Function Model in Diffraction Line-Broadening Analysis, Internatio. New York: Oxford University Press, 1999.

[13] L. B. McCusker, R. B. Von Dreele, D. E. Cox, D. Louër, and P. Scardi, "Rietveld refinement guidelines," J. Appl. Crystallogr., vol. 32, no. 1, pp. 36-50, 1999.

[14] N. K. Thanh, T. T. Loan, L. N. Anh, N. P. Duong, S. Soontaranon, N. Thammajak, and T. D. Hien, "Cation distribution in $\mathrm{CuFe}_{2} \mathrm{O}_{4}$ nanoparticles: Effects of Ni doping on magnetic properties," J. Appl. Phys., vol. 120, no. 14, p. 142115, 2016.

[15] C. Cheng, Y. Wen, X. Xu and H. Gu, "Tunable synthesis of carboxyl-functionalized magnetite nanocrystal clusters with uniform size,” J. Mater. Chem., vol. 19, pp. 8782-8788, 2009. 
[16] Z.-Q. Jin, W. Tang, J.-R. Zhang, H.-X. Qin, and Y.-W. Du, "Effective magnetic anisotropy of nanocrystalline NdFe-Ti-N hard magnetic alloys,” Eur. Phys. J. B, vol. 3, no. 1, pp. 41-44, 1998.

[17] J. Jiang and Y. M. Yang, "Facile synthesis of nanocrystalline spinel $\mathrm{NiFe}_{2} \mathrm{O}_{4}$ via a novel soft chemistry route," Mater. Lett., vol. 61, no. 21, pp. 4276-4279, 2007.

[18] D. T. T. Nguyet, N. P. Duong, L. T. Hung, T. D. Hien, and T. Satoh, "Crystallization and magnetic behavior of nanosized nickel ferrite prepared by citrate precursor method,” J. Alloys Compd., vol. 509, no. 23, pp. 6621-6625, 2011.

[19] R. D. Shannon, "Revised effective ionic radii and systematic studies of interatomic distances in halides and chalcogenides," Acta Crystallogr. Sect. A, vol. 32, no. 5, pp. 751-767, 1976.

[20] A. Ahadpour Shal and A. Jafari, "Study of Structural and Magnetic Properties of Superparamagnetic $\mathrm{Fe}_{3} \mathrm{O}_{4}-\mathrm{ZnO}$ Core-Shell Nanoparticles,” J. Supercond. Nov. Magn., vol. 27, no. 6, pp. 1531-1538, 2014. 